\title{
La céramique médiévale de Cergy-Pontoise, premiers résultats
}

\author{
Fabienne Ravoire
}

\section{(2) OpenEdition}

1 Journals

Édition électronique

URL : https://journals.openedition.org/cem/699

DOI : 10.4000/cem.699

ISSN : 1954-3093

\section{Éditeur}

Centre d'études médiévales Saint-Germain d'Auxerre

\section{Édition imprimée}

Date de publication : 15 août 2005

ISSN : 1623-5770

Référence électronique

Fabienne Ravoire, "La céramique médiévale de Cergy-Pontoise, premiers résultats », Bulletin du centre d'études médiévales d'Auxerre | BUCEMA [En ligne], 9 | 2005, mis en ligne le 18 octobre 2006, consulté le 22 septembre 2022. URL : http://journals.openedition.org/ cem/699; DOI : https://doi.org/10.4000/cem.699

Ce document a été généré automatiquement le 22 septembre 2022.

Creative Commons - Attribution - Pas d'Utilisation Commerciale - Partage dans les Mêmes Conditions 4.0 International - CC BY-NC-SA 4.0

https://creativecommons.org/licenses/by-nc-sa/4.0/ 


\title{
La céramique médiévale de Cergy- Pontoise, premiers résultats 1
}

\author{
Fabienne Ravoire
}

1 Les fouilles de l'église Saint-Christophe de Cergy-Pontoise ont livré un millier de tessons de céramiques. Leur répartition en fonction des contextes de découvertes montre qu'ils proviennent très largement du comblement des sépultures $(51 \%)$ mais également des niveaux de construction de l'édifice ( $43 \%$ ), et dans une faible mesure du comblement des fosses et silos (6\%).

2 Chronologiquement, les céramiques concernent une période longue comprise entre le $\mathrm{V}^{\mathrm{e}}$ siècle et le XVIII ${ }^{\mathrm{e}}$ siècle. La répartition des tessons en fonction de leur datation fait apparaître une forte représentativité des céramiques du bas Moyen Âge ( $45 \%)$, suivie par les céramiques du haut Moyen Âge et du Moyen Âge classique (36\%), et enfin par les céramiques modernes ( $9 \%$ ).

3 Les trois quarts des céramiques du haut Moyen Âge datent de la fin de la période carolingienne. Les productions déterminées pour cette période sont classiques pour l'île-de-France, c'est-à-dire des céramiques en pâte fine à décor engobé poli ou lissé, des céramiques en pâte à grosses inclusions de quartz dites pâte "granuleuse" et des pâtes sableuses $^{2}$. Mais nous trouvons à Cergy un groupe de pâte particulier, qui se caractérise par une matrice argileuse homogène proche de celle des pâtes sableuses, mais avec des inclusions de quartz de tailles moyennes. Les récipients identifiés sont des récipients culinaires et quelques fragments de cruches. Les céramiques des $\mathrm{XI}^{\mathrm{e}}$ et $\mathrm{XII}$ siècle sont également des productions utilitaires composées de pots à cuire et de pichets en pâte sableuse blanche.

4 L'intérêt céramologique du site réside surtout dans l'étude des ensembles du bas Moyen Âge qui, malgré le caractère extrêmement fragmentaire du mobilier recueilli, sont les plus riches d'informations. Il s'agit d'un mobilier à vocation liturgique. Les récipients utilisés sont de deux types: des pots traditionnellement utilisés pour des fonctions culinaires, dénommés oules (pots sans anse) et coquemars (pots avec une anse), et des pots à liquide, godets et pichets. 
5 Les premiers sont des productions locales. Ce sont des pots de petites tailles, aux parois extrêmement fines. Ils ont été réutilisés comme pots à encens, et ont, à ce titre, été perforés après cuisson du vase, à mi-panse sur une rangée. Leur surface interne est ainsi fortement noircie. En plus de deux pots trouvés intacts, cinquante-cinq autres ont pu être restitués. Le dépôt de récipients afin d'y faire brûler de l'encens est très répandu en France, particulièrement du XIII ${ }^{e}$ au XVI ${ }^{e}$ siècle. Un auteur du XIII ${ }^{e}$ siècle, Guillaume Durand, voit dans cet usage au mois trois significations: l'une, pratique - pour dissiper les mauvaises odeurs -, et les deux autres plutôt d'ordre symbolique ${ }^{3}$. En effet, l'encens permettait d'intercéder auprès du défunt. Il servait aussi de marqueur, car en laissant dans les tombes du charbon de bois qui se conservait longtemps, il indiquait aux survivants que la terre "ne pouvait plus servir à un usage profane" 4 .

6 Les pots à liquide sont nettement moins nombreux que les pots à encens. Ce sont d'une part, des pichets à décor d'appliques (pastilles et bandes verticales pincées) sur un fond d'engobe rouge avec glaçure jaune provenant de Poissy (Yvelines) ${ }^{5}$ et, d'autre part, des godets et pichets en grès importés du Beauvaisis. Ces récipients ne sont pas perforés, ni porteurs de traces d'encens. Il pourrait s'agir de pots destinés à contenir de l'eau bénite. En fait, Guillaume Durand évoque aussi la pratique qui consistait à utiliser de l'eau bénite pour écarter les démons ${ }^{6}$. Le fait qu'il s'agisse effectivement de récipients communément utilisés sur la table pour le service des liquides, plaide en faveur d'une telle attribution liturgique.

7 La récurrence de certaines associations permet de proposer une chronologie relative des enfouissements. On a pu observer qu'aucune des tombes ayant livré des fragments d'oules n'a livré de fragments de coquemars et inversement. Par ailleurs, les tombes avec oules sont parfois accompagnées de pichets "très décorés" mais jamais de godets en grès. Au contraire, les tombes avec coquemars contiennent parfois de pichets et godets en grès $\mathrm{du}$ Beauvaisis mais jamais de pichets "très décorés". Chronologiquement, les pichets "très décorés", sont répandus dans la première moitié $\mathrm{du} \mathrm{XIV}^{\mathrm{e}}$ siècle tandis que les pichets et godets en grès sont essentiellement diffusés à partir du milieu du siècle. La présence dans une des plus anciennes tombes du site qui est à coffrage, d'une oule et d'une monnaie de 1355, permet de dater les tombes avec oules de cette période. L'association des coquemars avec les récipients en grès, diffusés dans la deuxième moitié du siècle, situe les tombes avec coquemars peu après cette période. D'autres différences caractérisent ces séries de tombes, celles avec oules sont peu nombreuses ne contenant pas plus de deux récipients, alors que celles avec coquemars sont beaucoup plus fréquentes et avec un nombre de pots par tombe qui peut être très élevé (jusqu'à dix récipients). Cette multiplication des pratiques d'inhumation avec vases dans la deuxième moitié du XIV ${ }^{\text {e }}$ siècle a par ailleurs été constatée sur des ensembles funéraires d'Orléans ${ }^{7}$.

8 Pour conclure, il semble possible d'établir un lien entre le statut des inhumés et la présence des pots à eau. En premier lieu, ces récipients se trouvaient dans peu de tombes, quelle que soit la période. Ensuite, il ne s'agit pas de productions ordinaires mais bien de productions de qualité, contrairement aux pots à encens utilisés à Cergy qui sont à l'origine des pots de cuisson. Cette impression est renforcée par la présence de ces pots dans deux des quatre tombes privilégiées en coffrage. L'une était associée à un pichet "très décoré", la seconde à deux godets en grès dont un, assez rare, avec 
décor incisé. Ces éléments de réflexion demandent bien évidemment à être enrichis dans le cadre des recherches à venir.

\section{NOTES DE FIN}

1. Cette importante fouille a été réalisée par le Centre d'études médiévales en 2002 sous la direction de Samuel Riou (Cem). Sa publication est en cours.

2. A. LEFÈVRE, N. MAHE, "La céramique du haut Moyen Âge en Île-de-France à travers la fouille des habitats ruraux (VIe-XIe siècle). État de la question et perspectives de recherches", Céramiques domestiques et terre cuites architecturales au Moyen Âge, Actes des journées d'étude d'Amiens (2001-2002-2003), 2004, p. 10-24. (Revue archéologique de Picardie, $\left.\mathrm{n}^{\circ} 3 / 4\right)$.

3. GUILLAUME DURAND 1284, Rational ou Manuel des divins offices, trad. C. Barthélémy, Paris, 1854, LIII, chap. XXXVII, cité dans M. DURAND, “Archéologie du cimetière médiéval au sud-est de l'Oise. Relations avec l'habitat et évolution des rites et des pratiques funéraires du VIe au XVIe siècle", Revue archéologique de Picardie, numéro spécial, 1988, p. 191.

4. GUILLAUME DURAND, op. cit.

5. A. BOIVIN, D. DUfOURNIER, E. LECLER, "Nouvelles données sur la céramique très décorée rouennaise", La céramique très décorées dans l'Europe du Nord-Ouest (Xe-XVe siècle) Actes du colloque de Douai (7-8 avril 1995). Travaux du groupe de Recherches et d'Études sur la céramique dans le Nord-Pas-de-Calais, 1996, p. 61-84. (Nord-Ouest Archéologie, $n^{\circ} 7$ ).

6. M. DURAND, op. cit., p. 191.

7. D. ORSSAUD, "La céramique médiévale orléanaise", Revue Archéologique du Loiret, n 11, 1985, p. 62.

\section{INDEX}

Mots-clés : céramique

Index géographique : France/Cergy-Pontoise 